\title{
'URUF MAJMUK: KONSEP DAN AMALANNYA DALAM MASYARAKAT MAJMUK DI MALAYSIA
}

\section{The 'Urf of Plural Society: The Concept and Its Practices in Malaysia}

\author{
Mohd Anuar Ramli * \\ Mohammad Aizat Jamaludin **
}

\begin{abstract}
A plural society is a special feature of a country that has been colonized. This plurality is parallel to the racial and religious differences. In addition, it is also related to the cultural differences, residential segregation, dissimilar nature of work etc. Nowadays, the gap between the races has been reduced as a result of greater unity campaigns organized by the government. Consequently there has been interaction and cooperation between ethnic groups in Malaysia. With the introduction of new practices within the society, particularly the "open house" during festival seasons, the space for social contact between cultures-religions is flourishing. However, there are various conflicts between ethnic groups that could threaten the harmonious circumstances within the Malaysian society. Thus, this article attempts to elaborate upon the plurality of customs, its establishment through certain practices, especially “open house”, and its relevance in boosting national integration.
\end{abstract}

Keywords: Plural Society, Conflict, 'Urf, Open House, National Integration

* Pensyarah, Jabatan Fiqh \& Usul, Akademi Pengajian Islam, Universiti Malaya.

** Pegawai Penyelidik Sosial, Laboratori Polisi dan Pengurusan, Institut Penyelidikan Produk Halal (IPPH), Universiti Putra Malaysia. 


\section{PENDAHULUAN}

Etnik perkauman merupakan ciri penting masyarakat Malaysia. Kepercayaan agama, perbezaan bahasa, pengkhususan ekonomi, sikap politik dan bentuk kediaman kesemuanya secara kasar selari dengan pengenalan kumpulan etnik. ${ }^{1}$ Walaupun fenomena tersebut telah 38 tahun dikaji, namun kenyataannya hingga kini masih relevan dengan perkembangan realiti semasa. Menurut Harold Crouch:

By the late 1990s, Malaysian society was still divided along communal lines. Each ethnic community had its own distinct sense of identity. ${ }^{2}$

Di sesetengah negara, perbezaan kaum telah melahirkan amalan diskriminasi malah mencetuskan keganasan. Beberapa insiden perkauman sehingga ke peringkat genocide berlaku di beberapa buah negara seperti di Bosnia, Rwanda, Ambon dan Maluku di Indonesia. Senario di Malaysia masih lagi terkawal walaupun dalam catatan sejarahnya berlaku beberapa insiden antara kaum dan agama seperti 13 Mei 1969, peristiwa Kampung Medan dan seumpamanya. Selain insiden yang melibatkan pertentangan fizikal antara kaum dan agama tersebut, wujud juga beberapa isu yang sensitif yang menimbulkan ketidak puasan hati antara kaum, seperti isu kepala lembu yang diarak, kepala babi di dalam masjid, terbitan al-Kitab dalam bahasa Melayu, novel interlok dan sebagainya. Menginsafi tragedi dan insiden yang berlaku ini, satu langkah proaktif perlu dilaksanakan untuk mengeratkan ikatan batin antara penduduk Malaysia dalam suasana kasih sayang, hormat menghormati, bantu membantu dan interaksi yang berlangsung dalam masyarakat penuh dengan toleransi dan harmoni. Selaras dengan itu, kerajaan telah melaksanakan pelbagai kempen dan program integrasi antara kaum dalam rangka

Paul Douglas Marshall Starr (1973), Status Consistency and Marginality: A Study of Self and Society in Malaysia. Ann Arbor Michigan: University Microfilms, hh. 45-46.

2 Harold Crouch (2001), "Managing Ethnic Tensions Through Affirmative Action: The Malaysian Experience" dalam Nat J. Colletta et al. (eds.), Social Cohesian and Conflict Prevention in Asia: Managing Diversity through Development. Washington: The World Bank, h. 244. 
meminimumkan jurang heterogeniti antara kaum. Antara kempen yang dikemukakan adalah kempen penghayatan rukun negara, mewujudkan sekolah wawasan, perkongsian bilik antara kaum di asrama dan rumah terbuka dalam musim perayaan utama antara pelbagai kaum. Program rumah terbuka yang diperkenalkan ini tidak terdapat di tempat lain dan merupakan satu bentuk uruf majmuk di Malaysia. Idea ini telah diterapkan oleh kerajaan dan diamalkan oleh syarikat swasta serta orang perseorangan dalam meningkatkan persefahaman antara kaum. Walaupun begitu, amalan ini telah mengundang polemik pro dan kontra, terutamanya dari perspektif hukum Islam. Justeru, kajian ini akan membincangkan tentang uruf majmuk serta implementasinya dalam amalan rumah terbuka sebagai satu mekanisme integrasi nasional dengan mengambil kira prinsip syariat Islam di samping nilai-nilai universal antara kaum yang boleh dijadikan asas dalam amalan tersebut.

\section{KONSEP 'URUF MAJMUK}

'Uruf majmuk merupakan satu konsep yang baharu, serta tiada pentakrifan yang jelas. Walaupun dari aspek praktikalnya, ia telah lama menjadi kebiasaan dalam masyarakat majmuk di Malaysia. Konsep ini tersusun daripada dua perkataan yang mempunyai pemaknaan tersendiri, iaitu "uruf" dan "majmuk". Secara etimologinya perkataan uruf berasal dari perkataan Arab, iaitu 'arafa yang bererti mengetahui. Al-Jurjān̄̄ (m.816H) di dalam al-Ta'rífät, menjelaskan istilah 'uruf sebagai perbuatan atau kepercayaan dalam mana orang berpegang teguh dengan kekuatan mental dan secara semula jadi, mereka juga mahu menerimanya sebagai benar. ${ }^{3}$ Al-Zuhaylī mendefinisikan uruf sebagai kebiasaan yang diterima umum dan berakar umbi dalam masyarakat. Manakala Abū Zahrah menghuraikan 'uruf sebagai perkara yang menjadi kebiasaan orang ramai dalam transaksi ( $m$ ' 'àmalah) dan mereka bersikap konsisten dalam urusan mereka. ${ }^{4}$ Perbincangan tentang 'uruf dari aspek konseptual banyak dihuraikan di dalam

\footnotetext{
3 'Alī b. Muhạmmad al-Jurjānī (1405), al-Ta 'rîfât. Bayrūt: Dār alKitāb al-'Arabī, h. 193.

4 Muhammad Abū Zahrah (1958), Ușūl al-Fiqh. al-Qāhirah: Dār alFikr al-'Arabī, h. 216.
} 
kitab Usul al-Fiqh. Secara umumnya, konsep 'uruf mempunyai kaitan rapat dan makna yang sama dengan istilah adat atau custom dalam disiplin Antropologi Budaya.

Manakala perkataan majmuk dari segi etimologi berasal dari bahasa Arab majmu' yang beerti dihimpunkan atau yang terkumpul. Namun ia telah diterima dalam kosa kata bahasa Melayu sebagai terdiri atau terbentuk daripada beberapa bahagian dan sebagainya tetapi merupakan satu kesatuan. ${ }^{5}$ Dalam disiplin sosiologi, perkataan majmuk biasanya merujuk kepada bentuk masyarakat. Ia adalah keadaan yang mana terdapat beberapa masyarakat yang tinggal sebelah menyebelah di dalam satu unit politik yang sama tetapi dalam beberapa hal, hidup mereka terpisah. Setiap masyarakat mempunyai kepercayaan agama, kebudayaan, bahasa, idea dan cara hidup yang tersendiri. Pembahagian masyarakat atau kaum ini berlanjutan dalam sektor ekonomi di mana terdapat pembahagian jenis pekerjaan berasaskan bangsa ${ }^{6}$. Pendek kata, masyarakat majmuk yang berkembang di Malaysia boleh dilihat dalam empat dimensi iaitu politik, ekonomi, sosial dan budaya. ${ }^{7}$

Sehubungan pemaknaan bahasa tersebut, penulis merumuskan uruf majmuk merupakan suatu perbuatan atau amalan yang dilakukan secara berulang kali oleh masyarakat, bersifat positif dan ia membentuk satu kebiasaan yang diterima ramai. Dalam konteks Malaysia, ia merupakan amalan masyarakat majmuk serta pelbagai kaum, agama, bangsa, bahasa dan budaya, yang mengamalkan satu amalan baik dan ia tidak bertentangan dengan prinsip Syariah Islam.

Dalam pengambilkiraan 'uruf majmuk ini, terdapat beberapa pensyaratan yang perlu diambil kira, agar ia selari dengan prinsip syariat, iaitu:

5 Noresah Baharom et al. (eds.), (2005), Kamus Dewan. Edisi keempat, Kuala Lumpur: Dewan Bahasa dan Pustaka, h. 978.

$6 \quad$ John Sydenhem Furnivall (1956), Colonial Policy and Practice: A Comparative Study of Burma and Netherlands India. New York: New York University Press, h. 304; John Sydenhem Furnivall (1967), Netherlands India: A Study of Plural Economy. Cambridge: Cambridge University Press, h. 446.

7 Maurice Freedman (1960), "The Growth of a Plural Society in Malaya," dalam Pacific Affairs. v. 3, h. 159. 
i. 'Uruf itu tidak berlawanan dengan nas syarak sama ada alQuran atau al-Sunnah, sebaliknya jika ia berlawanan dengan nas, maka uruf tersebut tidak boleh diambilkira dan diamalkan seperti transaksi berunsur riba, pendedahan aurat dan sebagainya.

ii. 'Uruf itu diamalkan secara menyeluruh dan meluas oleh masyarakat. Kalau pun ada yang tidak mengamalkannya hanya dalam jumlah yang minimum.

iii. 'Uruf yang akan dirujuk dalam sesuatu tindakan itu sudah wujud ketika hendak dilakukan tindakan itu. Ertinya, uruf itu telah mendahului waktu tindakan dan berterusan sehingga masa berlakunya tindakan itu.

iv. Tidak wujud sesuatu perkataan atau perbuatan yang berterus terang menyalahi 'uruf. Maka tidak harus berpegang kepada uruf sekiranya terdapat perkataan dan perbuatan yang mengetepikan penggunaan uruf tersebut. ${ }^{8}$

Justeru, para ulama telah menggariskan beberapa panduan dan kriteria yang menjadi piawaian sebelum menerima sesuatu amalan itu sebagai baik atau tidak baik. Kriteria ini penting bagi memastikan uruf yang diamalkan itu selaras dengan ketetapan syariat Islam.

\section{LATAR BELAKANG MASYARAKAT MAJMUK DI MALAYSIA}

Malaysia merupakan sebuah masyarakat multi-rasial, multiagama yang mana Islam dominan dari segi politik mahupun budaya. ${ }^{9}$ Masyarakat Malaysia yang ada ditentukan oleh proses

8 Ismail Mat (1985), Adat and Islam in Malaysia: A Study in Legal Conflict and Resolution. Ann Arbor Michigan: University Microfilms, hh. 292-300.

$9 \quad$ Fred R. Von Der Mehden (1987), "Malaysia: Islam and Multi Ethnic Politics", dalam John L. Esposito (ed.), Islam in Asia: Religion, Politics and Society. New York: Oxford University Press, h. 177. 
sejarah khususnya kedatangan penjajah British ke Tanah Melayu. ${ }^{10}$ Melalui dasar "pintu terbuka", Tanah Melayu menjadi tumpuan golongan imigran dari China, India dan Indonesia. ${ }^{11}$ Aliran penduduk ini merupakan asas utama terdapatnya komposisi ras dan etnik di negara-negara yang pernah dijajah. ${ }^{12}$ Masyarakat majmuk di Malaysia merujuk kepada keadaan di mana masyarakat yang terdiri daripada golongan Eropah, ${ }^{13}$ Melayu, Cina dan India terpisah dari segi kaum atau bangsa, institusi, bentuk budaya, perbezaan politik dan kuasa ekonomi. ${ }^{14}$ Menurut Tregonning, bermula tahun 1870-an masyarakat Tanah Melayu berbentuk multi-rasia ${ }^{15}$ tetapi pembentukan masyarakat majmuk (plural society) berlaku pada tahun 1910-an. ${ }^{16}$ Dengan kata lain ia merujuk kepada masyarakat yang mengandungi karakteristik heterogenus.

Inggeris melaksanakan polisi pecah dan perintah (divide and rule) terhadap masyarakat majmuk di Tanah Melayu. ${ }^{17} \mathrm{Di}$ antaranya, spesialisasi (pengkhususan) pekerjaan, segregasi

10 Edmund Terence Gomez (2000), “Tracing the Ethnic Divide: Race, Rights and Redistribution in Malaysia", dalam Joanna Pfaf-Czarnecka et al. (eds.), Ethnic Futures: The State and Identity Politics in Asia. London: Sage Publications, h. 168.

11 Collin E.R. Abraham (1997), Divide and Rule: The Roots of Race Relations in Malaysia. Kuala Lumpur: Institute for Social Analysis (INSAN), hh. 2-3.

12 Malcolm Caldwell (1977), “The British Forward Movement 18741914”, dalam Mohamed Amin \& Malcolm Caldwell (eds.), Malaya: The Making of a New Colony. Nottingham: Spokesman Books, h. 29.

13 Lihat statistik taburan dan jumlah orang Eropah di Tanah Melayu dalam John G. Butcher (1979), The British in Malaya 1880-1941: The Social History of a European Community in Colonial Southeast Asia. Kuala Lumpur: Oxford University Press, hh. 24-27.

14 Graham Saunders (1977), The Development of a Plural Society in Malaya. Kuala Lumpur: Longman, h. 1.

15 Terdapat perbezaan penggunaan istilah masyarakat majmuk dengan masyarakat multirasial. Masyarakat majmuk merujuk kepada masyarakat heterogen sedangkan masyarakat multirasial tidak semestinya heterogen, kadangkala homogen.

16 K.G. Tregonning (1964), A History of Modern Malaya. London: Eastern University Press, h. 173.

17 B.N. Cham (1975), "Class and Communal Conflict in Malaysia", dalam Journal of Contemporary Asia. v. 5, h. 446. 
(pengasingan) tempat tinggal, pemisahan proses sosialisasi dan mobiliti, dan isolasi (pemencilan) budaya. ${ }^{18}$ Agama dan etnisiti merupakan faktor yang penting dalam masyarakat dan politik Malaysia kontemporari. ${ }^{19}$ Menurut Vasil, dua bentuk keadaan di Malaysia yang menentukan politik dan hubungan etnik, iaitu masyarakat bi-racial (dua bangsa) dari kalangan penduduk asal (indigenous) dan golongan imigran. Salah satu dari dua bangsa tersebut (penduduk asli dan pendatang lain) adalah kelompok yang utama. ${ }^{20}$

Bangsa Malaysia mono-etnik yang wujud pada awal sejarah negara Malaysia mengalami transformasi multi-dimensi sehingga bentuk dan sifat asalnya bertukar menjadi sebuah bangsa Malaysia multi-etnik. ${ }^{21}$ Istilah bangsa diturunkan statusnya kepada etnik untuk memberi laluan mewujudkan bangsa baru iaitu bangsa Malaysia multi-etnik. Kehadiran imigran Cina dan India yang mengekalkan kehidupan sosial dan identiti budaya mereka dalam suasana persekitaran baru menimbulkan kompleksiti struktur masyarakat Malaysia. ${ }^{22}$ Selain itu, merumitkan lagi keadaan apabila setiap kaum imigran terbahagi kepada sub-etnik yang lebih kecil. Justeru bertambah jurang perbezaan etnik-bahasa-agamaekonomi (ethnic-linguistic-religious-economic) yang homogen kalangan mereka. ${ }^{23}$

18 Lihat huraian Alvin Rabushka (1973), Race and Politics in Urban Malaya. California: Hoover Institution Press, hh. 19-27.

19 Hussin Mutalib (1990), Islam and Ethnicity in Malay Politics. Singapore: Oxford University Press, h. 1.

20 R.K. Vasil (1980), Ethnic Politics in Malaysia. New Delhi: Radiant Publishers, h. 2.

21 Lukman Z. Mohamad \& Khaidzir Hj. Ismail (2003), "Melayu Hilang di Dunia? Persoalan Identiti Nasional dan Bangsa Malaysia Dalam Era Globalisasi", dalam Lukman Z. Mohamad \& Azmi Abdul Manaf (eds.), Globalisasi di Malaysia. Kuala Lumpur: Utusan Publications, hh. 230-231.

22 S. Husin Ali (1965), "A Note on Malay Society and Culture", dalam S. Takdir Alisjahbana, Xavier S. T. Nayagam \& Wang Gungwu (eds.), The Cultural Problems of Malaysia in the Context of Southeast Asia. Kuala Lumpur: The Malaysian Society of Orientalists, h. 66.

23 Nancy Snider (1977), "Malaysian Non-Communal Political Parties", dalam John A. Lent (ed.), Cultural-Pluralism in Malaysia. Illinois: Northern Illinois University, h. 3. 
Selain pendatang dari negara China dan India, Tanah Melayu juga menjadi tumpuan imigran etnik Indonesia. Populasi Indonesia didominasi oleh etnik Jawa dan Banjar diikuti Sumatera (etnik Minangkabau, Mandailing, Kerinchi dan lainlain), Boyan dan Bugis. ${ }^{24}$ Imigrasi pelbagai etnik dari kepulauan Indonesia kemudiannya menjadi sebahagian populasi homogen bangsa Melayu $^{25}$ kerana persamaan keagamaan ${ }^{26}$ selain untuk mengimbangi komposisi heterogen kaum imigran dari China serta India dan juga kekuatan politik dan ekonomi bagi orang Melayu. ${ }^{27}$

Pengalaman dan takdir sejarah telah membentuk masyarakat majmuk Malaysia pada hari ini. Ia mengundang pelbagai masalah yang sukar dikikis dalam hubungan antara kaum di Malaysia. Dasar penjajah yang menjalankan polisi "pecah dan perintah" telah berjaya mewujudkan polarisasi antara kaum, spesialisasi pekerjaan dan segregasi tempat tinggal malah isolasi (keterasingan) budaya antara satu sama lain. Fenomena ini sekiranya berlanjutan akan menimbulkan krisis dan konflik yang kronik antara kaum. Justeru, 'uruf majmuk ini boleh dijadikan satu landasan integrasi nasional selaras dengan hasrat kerajaan Malaysia.

24 Lihat huraian Mohamed Aris Othman (1977), Ethnic Identity in a Malay Community in Malaysia. Ann Arbor Michigan: University Microfilms, h. 38.

25 Judith A. Nagata (1974), "What is a Malay? Situational Selection of Ethnic Identity in a Plural Society", dalam American Ethnologist. h. 337.

26 Berdasarkan Perlembagaan Persekutuan fasal 160(2)A :

“...seseorang yang menganut agama Islam lazimnya bercakap Melayu, menurut adat istiadat Melayu dan

a) Lahir sebelum Hari Merdeka di Persekutuan atau Singapura atau ibu bapanya lahir di Persekutuan atau di Singapura, atau pada hari Merdeka ini berdomisil di Persekutuan atau di Singapura atau;

b) Ia adalah keturunan seseorang yang tersebut."

Lihat Lembaga Penyelidikan Undang-undang (2001), Perlembagaan Persekutuan. Kuala Lumpur: International Law Book Services, h. 238.

27 Osman Chuah (2001), Chinese Muslims in Malaysia. Kuala Lumpur: International Islamic University Malaysia Press, h. 73. 


\section{ASAS PEMBINAAN 'URUF MAJMUK}

Pembinaan budaya bangsa Malaysia satu proses yang kompleks. Ia memerlukan kerangka asas (basic framework) yang mampu diaplikasikan untuk mendapat rupa bentuk bangsa yang diinginkan. Gagasan bangsa Malaysia merupakan keadaan anggota semua kaum harus mempunyai perasaan sebangsa dengan nama kolektif (bangsa Malaysia) yang sama serta berkongsi wilayah, ekonomi, budaya dan nasib masa depan bersama dengan rupa bangsa yang sepunya.

Gagasan ini telah menimbulkan reaksi berbeza kalangan pelbagai kaum. Orang bukan Melayu khususnya etnik Cina dan India, status mereka sebagai komponen satu bangsa baru (bangsa Malaysia) memang diharapkan kerana ia memberi legitimasi kebangsaan, namun dihantui kebimbingan dalam soal bahasa dan budaya kerana takut ditenggelami oleh etnik Melayu. Sedangkan orang Melayu tidak senang dengan status yang dikecilkan sebagai etnik sekalipun sebagai komponen utama dan pentakrif bangsa Malaysia. Walaupun begitu, disebabkan lanskap masyarakat Malaysia telah berubah, orang Melayu perlu memandang ke hadapan dengan mengambilkira peranan penting kaum lain demi keharmonian bersama. ${ }^{28}$

Sejajar dengan itu, integrasi antara kaum yang menjadi asas pembinaan bangsa Malaysia adalah antara matlamat utama beberapa dasar kerajaan yang telah digubal, contohnya, Dasar Perpaduan Negara, Dasar Pendidikan Negara, Dasar Kebudayaan Kebangsaan dan sebagainya. Begitu juga dengan penjanaan bangsa Malaysia (societal engineering) melalui Dasar Ekonomi Baru $^{29}$ selepas peristiwa 13 Mei 1969. Namun, kajian ini akan memfokuskan Dasar Kebudayaan Kebangsaan sahaja.

28 'Abd al-Rahman Embong (2000), Negara-Bangsa: Proses dan Perbahasan. Bangi: Penerbit Universiti Kebangsaan Malaysia, hh. 30-31.

29 Ghazali Shafie (2001), “Pembinaan Bangsa Malaysia”, dalam Isma 'il Hussein et al., Tamadun Melayu Menyongsong Abad ke-21. (edisi kedua), (cetakan kedua), Bangi: Penerbit Universiti Kebangsaan Malaysia, h. 174. 
Dasar Kebudayaan Kebangsaan adalah hasil rumusan Kongres Kebudayaan Kebangsaan pada tahun 1971 berdasarkan tiga prinsip: ${ }^{30}$

i. Kebudayaan kebangsaan Malaysia hendaklah berteraskan kebudayaan rakyat asal rantau ini.

ii. Unsur kebudayaan lain yang sesuai dan wajar boleh diterima menjadi unsur kebudayaan kebangsaan. ${ }^{31}$

iii. Islam menjadi unsur penting dalam pembentukan kebudayaan kebangsaan.

Dalam peruntukan ini terdapat tiga sumber kebudayaan yang boleh diguna pakai dalam mewujudkan bangsa Malaysia. Pertama budaya masyarakat Melayu, nilai-nilai budaya kaum lain yang sesuai $^{32}$ dan agama Islam. ${ }^{33}$ Sehubungan dengan itu, kerangka pembinaan bangsa Malaysia perlu bermula dengan prinsip-prinsip universal Islam sebagai paksinya. Kebudayaan Melayu boleh dijadikan pentakrif untuk pembinaan bangsa Malaysia melalui penggemblengan ciri-ciri positif dalam adat resam masyarakat Melayu sebagai penduduk peribumi negara ini. Setelah itu, baru diadunkan dengan ciri-ciri keperibadian dan budaya-budaya

30 "Konsep Kebudayaan Kebangsaan: Ke Arah Pemupukan dan Pengembangannya", dalam A. Aziz Deraman (ed.) (1978), Beberapa Aspek Pembangunan Kebudayaan Kebangsaan Malaysia. Kuala Lumpur: Kementerian Kebudayaan, Belia dan Sukan, hh. 12-17.

31 Konsep "sesuai" merujuk kepada unsur-unsur asing yang hendak diterima perlu melambangkan keperibadian Malaysia dan sesuai dengan norma-norma yang sedia ada. Lihat Noorsiah Sabri (1998), Pembangunan Kebudayaan Untuk Pembinaan Negara dan Bangsa. Kuala Lumpur: Kementerian Kebudayaan, Kesenian dan Pelancongan Malaysia, h. 18.

32 Agama Hindu dan Buddha adalah agama budaya.

33 Nilai-nilai universal Islam telah digubal dalam Dasar Penerapan Nilai-nilai Murni, iaitu amanah, tanggungjawab, ikhlas, sederhana, tekun dan lain-lain. Lihat Malaysia Kita. (1992), Kuala Lumpur: Institut Tadbiran Awam Malaysia (INTAN), h. 205. 
kaum lain di Malaysia. ${ }^{34}$ Idealnya, lahirlah bangsa Malaysia tanpa melibatkan perbezaan pengenalan etnik. ${ }^{35}$

Walaupun Dasar Kebudayaan Kebangsaan telah digubal dengan mengambil kira kepentingan semua pihak, ia bukan sahaja ditolak oleh golongan imigran Cina dan India semata-mata tetapi masyarakat asli Sabah dan Sarawak bukan Melayu yang tidak Islam lebih mendesak. ${ }^{36}$ Ini kerana berhubungan sejarah dan status sebagai kumpulan definitif, secara demografinya majoriti dan jaminan perlembagaan terhadap mereka. ${ }^{37}$

Merujuk kepada peruntukan Dasar Kebudayaan Kebangsaan, terdapat dua pilihan, iaitu pilihan positif dan pilihan negatif. Usaha untuk membentuk budaya Malaysia akan gagal sekiranya dasar Kebudayaan Kebangsaan ingin mewujudkan "bangsa Malaysia"

34 Wan Liz Ozman Wan Omar (2000), Mengurus Agenda Abad 21: Cabaran dan Persiapan Dalam Era Globalisasi. Kuala Lumpur: Golden Books Centre, hh. 70-71.

35 Terdapat empat pendekatan mengenai kebudayaan kebangsaan:

i. Pluralisme iaitu dianjurkan oleh gerakan politik bukan bumiputera terutama DAP dan MCA.

ii. Integrasi iaitu dianjurkan oleh golongan politik dan gerakan nasionalisme Melayu.

iii. Universalisme iaitu dianjurkan oleh gerakan sosial agama yang berpandukan nilai;

a. Lebih liberal dengan mengakui nilai-nilai sejagat dari semua kelompok.

b. Lebih tepat kepada nilai-nilai Islam sejagat.

iv. Akultrasi iaitu dianjurkan oleh golongan nasionalis pendidikan Barat yang berasaskan;

a. Keseimbangan pencapaian ekonomi.

b. Teras Melayu dan peribumi.

Lihat Zainal Kling (1987), "Konsep Kebudayaan Kebangsaan Malaysia" dalam Pertemuan Dunia Melayu '82. Kuala Lumpur: Dewan Bahasa dan Pustaka, h. 41.

36 Untuk maklumat lanjut mengenai ketidakpuasan hati golongan ini, sila rujuk Kua Kia Soong (ed.) (1987), Defining Malaysian Culture. Petaling Jaya: K. Das Ink, hh. 91-138.

37 Muhammad Ikmal Said (1996),"Malay Nationalism and National Identity", dalam Muhammad Ikmal Said \& Zahid Emby (eds.), Malaysia: Critical Perspectives. Kuala Lumpur: Persatuan Sains Sosial Malaysia, h. 56. 
sepenuhnya. Ini kerana untuk mencapai tahap tinggi dalam proses integrasi antara kaum bukanlah suatu proses yang mudah, tambahan pula, Islam diletakkan sebagai asas kebudayaan kebangsaan. Terdapat tiga faktor penting pengikat perpaduan negara, iaitu agama, keturunan dan kebudayaan. ${ }^{38}$ Ketiga-tiga unsur tersebut merupakan pemisah utama hubungan sosial masyarakat Malaysia. Hubungan antara kaum dalam realiti masyarakat Malaysia lebih berbentuk kontrak sosial ${ }^{39}$ yang bersendikan Undang-undang Perlembagaan ${ }^{40}$ dan Rukun Negara. ${ }^{41}$

Terdapat pilihan positif sekiranya Dasar Kebudayaan Kebangsaan bermatlamatkan melahirkan sebuah bangsa Malaysia yang mana masyarakat multi-rasial (bukan majmuk) dapat hidup dengan harmoni mengamalkan cara hidup masing-masing di dalam sebuah negara, tanpa penekanan dan pemaksaan unsur keagamaan dan perkauman, sebaliknya berasaskan konsensus nilai

38 Abdullah Nawi (1986), "Peranan Kebudayaan Kebangsaan dalam Integrasi Rakyat", dalam Cheu Hock Tong (ed.), Beberapa Asas Integrasi Nasional: Pro dan Kontranya. Kuala Lumpur: Penerbit Karya Kreatif, h. 96.

39 Kontrak sosial merupakan watikah asas keadilan sosial untuk negara yang dipersetujui ketika negara dibentuk. Lihat Mohamed Jawhar Hassan (1996), "Keadilan Sosial dan Hubungan Kaum dalam Konteks Masyarakat yang Berubah", Azizan Bahari \& Chandra Muzaffar (eds.), Keadilan Sosial. Kuala Lumpur: Institut Kajian Dasar (IKD), h. 147.

40 R.H. Hickling (1995), "Law and National Unity in Malaysia" dalam Koleksi Essei Undang-undang Sempena 25 Tahun UKM. Bangi: Penerbit Universiti Kebangsaan Malaysia, h. 24.

41 Pandangan yang diharap menjadi asas integrasi antara etnik ini telah diisytiharkan pada 31 Ogos 1969. Lihat, Ghazali Shafie (1978), Rukun Negara Pembentuk Masyarakat. Kuala Lumpur: Dinamika Kreatif, hh. 173-174. Terdapat pandangan yang menegaskan ideologi rukun negara bukan untuk menimbulkan satu perasaan identiti kebangsaan sebaliknya melahirkan satu perasaan komuniti politik yang kuat berasaskan sistem demokrasi. Lihat, David S. Gibbons (1989), "Perpaduan Nasional dan Kepelbagaian Kebudayaan di Malaysia", dalam Syed Ahmad Hussein \& Y. Mansoor Marican, Integrasi Politik. Kuala Lumpur: Dewan Bahasa dan Pustaka, h. 83. 
yang sama ${ }^{42}$ neutral dan universal. Kebudayaan kebangsaan perlu bersifat "selective" dalam memilih ciri-ciri yang dapat berlaku pada peringkat integrasi nasional.

Proses membina nilai-nilai bersama dapat diterokai berdasarkan mekanisme dialog peradaban dan inter-agama. ${ }^{43}$ Nilai bersama adalah nilai-nilai umum yang boleh dicungkil dari sistem-sistem agama tanpa membezakan sama ada itu Islam ataupun bukan Islam. Asas ini penting memandangkan nilai bersama sesebuah negara harus dibentuk dan dibina berasaskan keperluan seluruh masyarakat, bukan keperluan sesuatu kumpulan etnik dan agama tertentu. ${ }^{44}$ Sebagai contoh, sikap toleransi, kesederhanaan, kasih sayang, hormat menghormati, keperibadian agung, alami dan sebagainya. ${ }^{45}$

Sehubungan dengan itu, penekanan sistem aksiologi ini dapat diaplikasikan dalam usaha membina 'uruf majmuk di Malaysia. Sistem aksiologi Melayu berasaskan budi Melayu dan dapat dilihat dalam epistemologi Melayu. ${ }^{46}$ Manakala sistem aksiologi Islam berdasarkan wahyu iaitu al-Quran dan al-Sunnah, sedangkan

42 Chandra Muzaffar (2001), Rights, Religion and Reform: Enhancing Human Dignity Through Spiritual and Moral Transformation. London: Routledge \& Curzon, hh. 348-351.

43 Vincent J. Cornell (1994), "Towards a Cooperation Among People of Different World Religions", dalam Abdul Monir Yaacob \& Ahmad Faiz Abdul Rahman (eds.), Towards a Positive Islamic World-View. Kuala Lumpur: Institut Kefahaman Islam Malaysia (IKIM), h. 98.

44 Cheu Hock Tong (1986), "Peranan Nilai-nilai Bukan Islam Dalam Konteks Kebudayaan Kebangsaan", dalam Cheu Hock Tong (ed.), op.cit., h. 127.

45 Dalam disiplin peradaban, nilai ini dipanggil Asian values. Asian values merujuk kepada peradaban Timur yang didominasi oleh Islam, Konfusius, Buddha dan sebagainya. Lihat, Han Sung-Joo "Asian Values: An Asset or a Liability", dan Farish A. Noor (1999), "Values in the Dynamics of Malaysia's Internal and External Politic Relations", dalam Han Sung-Joo (ed.), Changing Values in Asia: Their Impact on Governance and Development. Singapore: Institute of Southeast Asian Studies, h. 3 dan 146.

46 Untuk maklumat mengenai epistemologi Melayu, lihat Hassan Ahmad (2003), Metafora Melayu: Bagaimana Pemikir Melayu Mencipta Makna dan Membentuk Epistemologinya. Kajang, Selangor: Akademi Kajian Ketamadunan, h. 32. 
sistem aksiologi kaum atau agama lain berasaskan nilai positif, universal dan sejagat yang tidak bercanggah dengan tradisi Melayu dan agama Islam.

Justeru, satu sistem nilai yang holistik perlu digunapakai untuk merealisasikan 'uruf majmuk yang berlatarkan realiti dan mentaliti tempatan. Pengambilkiraan sistem nilai Melayu dan Islam sebagai unsur utama pembentukan kebudayaan kebangsaan adalah faktor penguat kepada lahirnya gagasan sistem 'uruf majmuk di Malaysia selain unsur agama budaya lain.

\section{RUMAH TERBUKA MUSIM PERAYAAN: AMALAN BERLANDASKAN 'URUF MAJMUK}

Masyarakat Melayu sebagai teras bangsa Malaysia memiliki perbendaharaan nilai dan budi bahasa yang mulia dan terpuji seperti yang tersurat dan tersirat dalam pantun dan peribahasanya. ${ }^{47}$ Mereka menyanjung tinggi, memuji, menggalakkan dan menghargai budi bahasa yang mulia seperti berhati-hati, merendah diri, sabar, pemurah, menunaikan janji, muafakat, tolong menolong dan sebagainya. ${ }^{48}$ Semua amalan ini bersesuaian dengan ajaran Islam. ${ }^{49}$

Satu nilai positif lain yang terdapat dalam budaya Melayu adalah kunjung-mengunjungi serta ziarah-menziarahi. ${ }^{50}$ Ia menjadi amalan dalam perayaan umat Islam di Malaysia sama ada pada Hari Raya Aidil Fitri ataupun Aidil Adha. Daripada tradisi ziarah menziarahi masyarakat Melayu ini, lahirnya idea rumah terbuka

47 Untuk merujuk pelbagai nilai murni Melayu yang selaras dengan ajaran Islam, lihat Abdullah al-Qari Salleh (2002), Sinar Wahyu Menembusi Pantun Falsafah Melayu. Kuala Lumpur: al-Hidayah Publishers.

48 Ahmad Hj. Yusof (1959), Sarenjis Mawar. Port Wellesley: Pustaka Rumaja, h. 5.

49 Mustafa Daud (2002), "Budi Bahasa Dalam Tamadun Melayu dan Tamadun Islam: Satu Perbandingan" dalam Syed Muhammad Dawilah al-Edrus (ed.), Pemikiran Melayu Tentang Alam dan Hakikat Diri. Kuala Lumpur: Dewan Bahasa dan Pustaka, h. 110.

50 Mohtar H. Md. Dom (1977), Adat Perpatih dan Adat Istiadat Masyarakat Malaysia. Kuala Lumpur: Federal Publications, h. 45. 
pada setiap musim perayaan agama-agama masyarakat Malaysia. ${ }^{51}$ Amalan ini cuba dikembangkan oleh kerajaan sebagai program bersama dalam rangka mewujud dan memupuk perpaduan serta integrasi antara kaum.

Sepertimana yang diungkapkan oleh Dr. Mahathir Mohamad:

Di Malaysia di mana penduduknya terdiri daripada berbagai-bagai agama, sudah menjadi tradisi penduduknya merayakan perayaan semua kaum. Jika sesuatu kaum mengadakan sambutan hari raya, maka kaum-kaum yang lain turut bersama-sama merayakannya. Sama ada perayaan itu bercorak agama ataupun hanya adat resam sahaja seperti perayaan tahun baru, pesta menuai atau lain-lain perayaan seumpamanya yang dikaitkan dengan sesuatu kaum di Malaysia, maka apabila kaum berkenaan mengadakan hari raya, sетиa kaum turut bersama... Mereka kunjung-mengunjung untuk berjumpa kawan-kawan di hari perayaan kawan mereka itu supaya dapat bersama merayakannya, walaupun yang mengunjungi atau yang dikunjungi itu dari bangsa dan agama yang berlainan. ${ }^{52}$

Amalan ini tidak terdapat di kebanyakan negara lain. Setiap kaum merayakan perayaan masing-masing tanpa melibatkan kaum lain. Sebagai contoh di negara India, penganut Hindu tidak dapat hidup bersama orang Islam dan orang Sikh, tetapi di Malaysia, setiap kaum, kepercayaan dan amalan perayaan bebas dipraktikkan dan hidup dalam suasana yang harmoni.

Sehubungan dengan itu, satu pemahaman serta penilaian kembali terhadap tafsiran sarjana klasik mengenai pola hubungan orang Islam dengan bukan Islam perlu dilakukan selaras dengan

51 Lihat jenis-jenis perayaan masyarakat Malaysia dalam Taha Abdul Kadir (1985), Hari Perayaan Penduduk Malaysia. Petaling Jaya: Pelanduk Publications.

52 Mahathir Mohammad (1995), Tradisi Merayakan Perayaan Semua Kaum. Kuala Lumpur: Jabatan Perkhidmatan Penerangan Malaysia, c. 2, hh. 4-5. 
perkembangan dan realiti masa kini. ${ }^{53}$ Ia juga sejajar dengan semangat ajaran Islam serta gagasan Islam inklusif-pluralis. Proses ini penting dalam membina suatu hubungan yang akrab dengan penganut agama lain. Ia memerlukan suasana yang damai dan semangat perpaduan.

Dengan demikian, perasaan saling memusuhi, membenci dan mencurigai antara penganut agama dapat diminimumkan. ${ }^{54}$ Sehubungan dengan itu, uruf rumah terbuka penting untuk sebuah masyarakat majmuk seperti Malaysia pada realiti masa sekarang.

Selain itu, amalan rumah terbuka relevan dengan realiti masa kini bersandarkan beberapa perkara:

i. Menghayati saranan al-Quran dalam prinsip ta 'āruf (saling kenal mengenali). Kepelbagaian yang diciptakan oleh Allah SWT adalah untuk saling berkenalan. Manusia tidak mempunyai alternatiflain kecuali menerima dan memelihara realiti dan ketentuan Allah ini dengan mengarahkan kepada kepentingan dan tujuan bersama. ${ }^{55}$ Firman Allah SWT mafhumnya: ${ }^{56}$

Wahai umat manusia! Sesungguhnya Kami telah menciptakan kamu dari lelaki dan perempuan, dan Kami telah menjadikan kamu berbagai bangsa dan bersuku puak, supaya kamu saling berkenal-kenalan (dan beramah mesra antara satu dengan yang lain). Sesungguhnya semuliamulia kamu di sisi Allah ialah orang yang lebih takwanya di antara kamu, (bukan yang lebih keturunan atau bangsanya). Sesungguhnya

53 Untuk melihat perbincangan dalam kerangka klasik, rujuk Ridzwan Ahmad (2000), "Pengaruh Budaya Tempatan Terhadap Penentuan Hukum Menziarahi Rumah Terbuka Perayaan Agama Bukan Islam di Malaysia", dalam (Kertas kerja Seminar Hukum Islam Semasa III Peringkat Kebangsaan. Anjuran Akademi Pengajian Islam Universiti Malaya, Kuala Lumpur).

54 Lihat H. Abuddin Nata (2001), Peta Keragaman Pemikiran Islam di Indonesia. Jakarta: PT. Raja Grafindo Persada, h. 201.

55 Sahibi Naim (1983), Kerukunan Antara Umat Beragama. Jakarta: PT. Gunung Agung, h. 49.

56 Al-Quran, al-Hujurāt (49): 13. 
Allah Maha Mengetahui, lagi Maha mendalam pengetahuannya (akan keadaan dan amalan kamu).

ii. Selaras dengan keteladanan Nabi Muhammad SAW. Toleransi dan moderasi yang Baginda ajarkan harus sentiasa menjadi acuan dan pedoman dalam interaksi dengan penganut agama lain. ${ }^{57}$ Sirah Nabi Muhammad SAW mencatatkan bagaimana Baginda bersikap toleransi apabila berinteraksi dengan golongan bukan Islam. ${ }^{58}$ Contohnya, dalam perjanjian Hudaybiyyah, ${ }^{59}$ Baginda SAW bertolak ansur dengan karenah golongan kafir, tetapi Baginda bersikap tegas apabila perjanjian tersebut dilanggar oleh orang bukan Islam.

iii. Sejajar dengan konsep muhibah yang diamalkan dalam masyarakat Melayu klasik. Melaka sebuah bandaraya kosmopolitan telah didiami oleh berbagai jenis suku kaum. ${ }^{60}$ Perpaduan wujud hasil interaksi masyarakat tempatan dengan pedagang asing seperti Arab, Farsi, Cina, Tamil, Cettiar, Keling dan sebagainya. ${ }^{61}$

iv. Saling memahami kepekaan masing-masing berhubung dengan kecintaan serta ikatan batin dengan agama anutan. ${ }^{62}$ Pergaulan dengan golongan bukan Islam berprinsipkan fikiran positif melahirkan saling memahami dan saling

57 Alwi Shihab (1998), Islam Inklusif: Menuju Sikap Terbuka Dalam Beragama. Bandung: Penerbit Mizan, c. 4, h. 337.

58 Syed Othman Alhabshi \& Faisal Hj Othman (1996), "Principles of Tolerance in Islam and the Historical Practices" dalam Syed Othman Alhabshi \& Nik Mustapha Nik Hassan (eds.), Islam and Tolerance. Kuala Lumpur: Institute of Islamic Understanding Malaysia (IKIM), c. 2 , h. 57.

59 'Abdal-Mālik b. Hishāmal-Humayrī(1997), al-Sìrahal-Nabawiyyah. Bayrūt: Dār Iḥyā’ al-Turāth al-‘Arabī, juz. 3, h. 346.

60 Muhammad Yusoff Hashim (1983), "Masyarakat Melaka Zaman Kesultanan dan Sifat Kosmopolitannya" dalam Kernial Singh Sandhu \& Paul Wheatley (eds.), Melaka: The Transformation of a Malay Capital C. 1400-1980. Kuala Lumpur: Oxford University Press, hh. 122-123.

61 Perpaduan ini teruji dengan pencerobohan imperialis Portugis.

62 Alwi Shihab (1998), op.cit., h. 338. 
mengerti. Kesemua ini menghilangkan rasa asing antara golongan Islam dan bukan Islam. ${ }^{63}$

v. Saling hormat menghormati pegangan agama masingmasing untuk mencapai keharmonian antara kaum. Sikap ini penting untuk menghindari sebarang konflik sepertimana peristiwa 13 Mei yang merosakkan banyak harta benda malah mengorbankan jiwa.

vi. Selaras dengan prinsip toleransi. Wawasan Islam telah menjadi mantap akibat penerapan nilai kemelayuan. Gabungan Melayu Islam bukan sekadar telah membentuk sempadan akidah dan batasan budaya, tetapi telah menjadikan orang Melayu sebagai kaum yang toleran, berkesanggupan menerima kumpulan dan etnik lain. Yang pentingnya, setiap orang Islam dan bukan Islam haruslah memahami dasardasar toleransi Islam dan dasar-dasar hidup bersama di antara orang Islam dan bukan Islam. Islam bukan agama yang berasaskan paksaan ataupun agama yang menekan sesuatu golongan yang tertentu kerana dalam sejarah Islam, tidak ada satu pun peristiwa yang menunjukkan bahawa Islam memaksa atau menekan golongan bukan Islam. Sikap toleransi ini perlu dijana dan dijelmakan dalam amalan rumah terbuka untuk mencapai perpaduan antara kaum.

\section{KESIMPULAN}

Malaysia adalah sebuah negara unik kerana mempunyai rakyat yang terdiri daripada berbagai keturunan, bahasa dan agama di samping mempunyai berbagai-bagai adat resam dan budaya masing-masing. Namun begitu, masalah perpaduan antara kaum adalah satu masalah yang kritikal yang sukar dikendalikan sekiranya pemimpin negara tidak pandai menanganinya manakala rakyat pula tidak dapat bertolak ansur antara satu sama lain.

'Uruf majmuk merupakan amalan yang telah menjadi kebiasaan masyarakat Malaysia kini. Adat ziarah menziarahi musim perayaan orang Melayu-Islam telah diangkat menjadi tradisi nasional. Kini setiap perayaan besar lain seperti Tahun Baru Cina, Deepavali,

63 Sahibi Naim (1983), op.cit., h. 59. 
Krismas dan lainnya turut menganjurkan "rumah terbuka" bagi meraikan kehadiran penganut agama lain. Dengan amalan ini, diharap ia dapat menyumbang kepada perasaan muhibbah serta membentuk hubungan antara kaum yang lebih baik dalam konteks masyarakat majmuk di Malaysia, seterusnya integrasi nasional mencapai matlamatnya. 
Jurnal Fiqh, No. 8 (2011) 45-64 